\title{
La sexualidad en La vejez
}

\author{
Zeyda Rodríguez Morales
}

doi: https://doi.org//0.32870/eees.v27i77.7129

"Por eso escribo el libro: para quebrar la conspiración del silencio"

Una obra muy poco conocida de Simone de Beauvoir es el último ensayo que escribió, titulado La vejez, que fue publicado en 1970, cuando ella tenía sesenta y dos años y estaba aún a dieciséis de morir, en 1986. Se trata de un amplio texto de más de setecientas páginas tras el cual se dedicó a escribir novelas y editar sus diarios. Su libro más famoso, El segundo sexo, ha capturado la atención sobre su obra desde el momento de su publicación, en 1949, y les ha restado importancia a sus trabajos posteriores que, a mi juicio, son igual de relevantes que aquel.

La vejez se organiza en dos grandes secciones. La primera se titula "El punto de vista de la exterioridad", y en ella da cuenta de una amplia investigación sobre la vejez de tipo biológica, histórica y sociológica, terrenos en los cuales la autora se mueve cómodamente no sólo asumiendo una mirada filosófica, sino también haciendo uso de una diversidad de disciplinas, teorías, autores y datos venidos de encuestas disponibles en su época, que permiten ver con detalle las

Simone de Beauvoir (2015). La vejez. México:

Penguin Random House. 
condiciones de vida de la población mayor en Francia y en varios países de Europa.

Esta visión de la vejez desde su presente tiene como antecedente la reconstrucción histórica de las concepciones sociales de la misma, desde las Grecia y Roma antiguas, pasando por la Edad Media, hasta llegar al siglo Xx.

La segunda parte del libro lleva por nombre "El ser en el mundo", y en ella el tema central es lo subjetivo, la exploración de la experiencia de ser viejos ${ }^{1} \mathrm{y}$ el lugar predominante que tienen en este proceso el cuerpo y su percepción del tiempo. En este caso, sus fuentes más usadas son cartas y diarios personales de gran número de personajes, principalmente hombres y miembros de sectores acomodados económicamente -como algunos políticos prominentes-, esto por ser ellos quienes más frecuentemente dejaron testimonio de su vida. Asimismo, abundan en esta segunda parte fragmentos venidos de la obra literaria de grandes y reconocidos escritores, que dejaron para la posteridad sus reflexiones en torno justamente a la vivencia de la vejez. En esta sección se concentran las reflexiones de la autora sobre la sexualidad en esta etapa de la vida, tema central de esta reseña.

De forma similar a lo que escribió en $E l$ segundo sexo (De Beauvoir, 2013) respecto de las mujeres, donde argumentaba que no existe una determinación biológica que defina su subjetividad, ni mucho menos sus roles sociales, emociones y sentimientos, en el caso de los viejos y las viejas, De Beauvoir sostiene que su condición de vida no deriva de la simple llegada a cierta edad, los sesenta y cinco años en el caso de Francia, porque cada sociedad define las formas posibles de vivir tal condición, no sólo físicamente, sino en términos de reconocimiento, valoración, acceso a derechos,

I. Usaré los términos viejos y viejas por ser comunes en la literatura al respecto, en un afán por desdramatizar moralmente la condición de la vejez y renunciar al uso despectivo con que se utilizan en el habla del sentido común. 
exclusión o estigma: "El hombre no vive jamás en estado de naturaleza; en su vejez, como en cualquier edad, su condición le es impuesta por la sociedad a la que pertenece" (p.15), dice la autora en el libro aquí reseñado.

Asimismo, para ella, las variables específicas que determinan lo que nutre esa condición también devienen del contexto particular de existencia de cada viejo, ya que la forma de experimentar su cuerpo pasa por las enfermedades que padeció y padece, la atención que tuvo y a la que tiene posibilidad de acceder, la calidad de su dieta, el lugar donde vive, las compañías y afectos con que cuenta, la relación con sus hijos (si los tuvo), y si tiene o no una pareja sentimental.

Tal vez movida por la situación que ella misma comenzaba a vivir, De Beauvoir señala: "No sigamos trampeando; en el futuro que nos aguarda está en juego el sentido de nuestra vida; no sabemos quiénes somos si ignoramos lo que seremos: reconozcámonos en ese viejo, en esa vieja. Así tiene que ser si queremos asumir en su totalidad nuestra condición humana" (p. 11).

Como mencioné ya, el asunto al que dedicaré este texto es el de la sexualidad de las personas mayores, que se enlaza al tema de los afectos, pero no obligadamente. Este asunto, como pocos, posee la cualidad de concentrar los juicios y valoraciones de una sociedad sobre sus viejos y sobre las normas que regulan y orientan su visión sobre la sexualidad en general. Ejemplo de esto es la siguiente frase de De Beauvoir: "Si los viejos manifiestan los mismos deseos, los mismos sentimientos, las mismas reivindicaciones que los jóvenes, causan escándalo, en ellos el amor, los celos parecen odiosos o ridículos, la sexualidad repugnante, la violencia irrisoria" (p. 10).

A pesar de tratarse de un texto sobre Francia, tal aseveración nos resulta completamente familiar en México. Aquí, como allá,

Reseñas No.77 
el tema de la vejez ha sido tratado casi siempre de manera estereotipada; las mismas comparaciones, los mismos adjetivos. Es el invierno de la vida. La blancura del pelo, de la barba, evocan la nieve, el hielo; hay una frialdad del blanco a la que se oponen el rojo -el fuego, el ardor-y el verde, color de las plantas, de la primavera, de la juventud. (p. 202)

La visión de la sexualidad para esta autora es amplia y cercana a la concepción de Sigmund Freud sobre la libido, ya que la define como

una intencionalidad vivida por el cuerpo, que apunta a otros cuerpos y se amolda al movimiento general de la existencia. Se inviste en el mundo al que confiere una dimensión erótica. Interrogarse sobre la sexualidad de los viejos es preguntarse en qué se convierte la relación del hombre consigo mismo, con los demás, con el mundo, cuando ha desaparecido en la organización sexual el primado de la genitalidad. (p. 393)

Los viejos, afirma la autora, a quienes se les niega socialmente ser sujetos sexuados, no tendrían ninguna razón para renunciar a la sexualidad:

el viejo desea a menudo desear, porque conserva la nostalgia de experiencias insustituibles, porque permanece unido al universo erótico que ha construido en su juventud o su madurez; por el deseo reanimará sus colores empalidecidos. Y también por el deseo experimentará su propia integridad. (p. 395)

No obstante, agrega, existe una gran heterogeneidad en la forma como los viejos se posicionan ante la sexualidad. Quienes luchan frente a los estereotipos y el estigma social son quienes le han conferido un valor positivo a lo largo de su vida. En cambio, "los que sólo se entregaban a ella con repugnancia, como consecuencia de complejos arraigados en la infancia, se apresuran a invocar la edad para dispensarse" (pp. 395-396).

\section{6}


A esto, agrega De Beauvoir, se aúna la condena social, la cual puede llegar a ser tan efectiva que aun quienes

han tenido una vida sexual feliz pueden tener razones para no querer prolongarla. Una de ellas es [...] el disgusto del propio cuerpo [...], otra barrera es la presión de la opinión. La persona de edad se pliega al ideal convencional que le es propuesto. Teme el escándalo o simplemente el ridículo. Se vuelve esclava del qué dirán [...]. Sus propios deseos la avergüenzan, los niega; se rehúsa a ser ante sus propios ojos un viejo lúbrico, una vieja desvergonzada. (p. 396)

En este punto, la autora reconoce que es necesario hacer mucha más investigación empírica sobre estos temas, pues el conocimiento sobre el comportamiento de los viejos y las viejas en realidad es poco. Por ejemplo, declara, se saben por estadísticas varias cosas, como que la frecuencia de los coitos disminuye con la edad, aunque con diferencias entre los sujetos, pues hay personas de sesenta años sin ninguna actividad sexual y otras de ochenta muy activas.

Estas variaciones se explican por variables como el estado civil, ya que los coitos son más numerosos entre los viejos casados que entre los solteros y los viudos; por otra parte, los miedos de no lograr una erección o de no satisfacer a la compañera son más comunes entre los solteros y viudos que entre los casados, vinculados con una esposa que es comprensiva ante dicha posibilidad.

No obstante, entre los casados también disminuyen los coitos, pues

al avanzar en edad, se fatiga[n] de una compañera demasiado conocida, sobre todo que ella ha envejecido y ya no le[s] parece deseable. Cuando tienen posibilidad, muchos hombres de edad recobran el vigor viril cambiando su vieja compañera por una nueva que eligen en general joven. (p. 398)

Reseñas No.77 
Y prosigue recordando que para los solteros quedan como opción los amores venales por medio de prostitutas o con mujeres a las que ayudan económicamente. Otra solución muy frecuente es el onanismo, que ocurre también entre los casados, a razón de que su esposa se niega ya a tener una vida sexual.

En lo que respecta a la condición social, De Beauvoir encuentra que en Francia, en el momento cuando escribe,

las relaciones sexuales se prolongan más entre los trabajadores manuales que entre los intelectuales, en los hombres cuyo nivel de vida es bajo que en los de las clases acomodadas. Los obreros, los campesinos tienen deseos más directos, menos sometidos a los mitos eróticos que los burgueses. (p. 400)

A dichos hombres, señala la autora, los cuerpos de sus mujeres, aun viejas, no les parecen tan arruinados, y ellos se sienten menos molestos por la presión social.

En referencia a la duración de la vida sexual, De Beauvoir afirma que esta "se prolonga tanto más cuanto más rica y más feliz ha sido. [...] Si sus actividades sexuales han sido espontáneas y gozosas, [el viejo] insistirá en continuarlas hasta el límite de sus fuerzas" (p. 400). Asimismo, los viejos buscan además satisfacciones indirectas, tales como lecturas eróticas, obras de arte libertinas, chistes picantes, fetichismo, sadomasoquismo, perversiones directas, voyerismo y contacto con mujeres jóvenes. Agrega: "sexualidad, salud, vitalidad, van unidas; se diría que la vida del individuo está programada desde el punto de partida; a menos de accidentes venidos desde el exterior, su energía vital como su longevidad están inscriptas en su organismo" (p. 416).

Prosiguiendo sus reflexiones, pero aguzando la mirada sobre la distinción por género, De Beauvoir es tajante cuando afirma: "el caso de los hombres es muy diferente del de las mujeres. Biológicamente, los hombres están en 
mayor desventaja; socialmente, la condición de objeto erótico desfavorece a las mujeres" (p. 397). En otro punto, agrega: "biológicamente la sexualidad de la mujer es menos afectada por la vejez que la del hombre" (p. 428).

Citando a autores clave en la comprensión de la vida sexual, De Beauvoir argumenta sus afirmaciones:

según Kinsey, a lo largo de toda la vida hay mayor estabilidad sexual en la mujer que en el hombre; a los sesenta años, sus posibilidades de deseo, de placer, son las mismas que a los treinta años. Para Masters y Johnson [...] la mujer sigue siendo capaz de llegar al orgasmo, sobre todo si es objeto de estímulo sexual eficaz y regular [...]. Añado que a la mujer puede gustarle hacer el amor, aunque no llegue al orgasmo [...]. Es menos sensible a la apariencia de su pareja y en consecuencia menos afectada por su envejecimiento [...]. Puede cumplir actividades sexuales hasta sus últimos días. Sin embargo, todas las encuestas muestran que sus actividades son de hecho mucho menos numerosas que las de los hombres. (p. 429)

Justo en este punto, enlaza el texto con su reconocida perspectiva feminista, y agrega: "Es que socialmente el hombre, a toda edad, es sujeto, y la mujer un objeto, un ser relativo" (p. 430). Amplía su argumento al decir que para las mujeres de edad es muy difícil tener relaciones extramaritales, pues no gustan a los hombres como las jóvenes. Es decir, la autora precisa que a los setenta años las mujeres ya no son un objeto erótico, y los amores venales son también difíciles para ellas, pues pocas pueden pagar a un hombre, además de que sienten vergüenza y temor al qué dirán. Muchas optan por masturbarse. De este modo, "la mujer sufre hasta el fin su condición de objeto erótico. La castidad no le es impuesta por un destino fisiológico, sino por su condición de ser relativo. Sin embargo, ocurre que ella misma se condena a la castidad a causa de esas 'barreras psíquicas”' (p. 431).

Reseñas No.77 
En este aspecto, se vuelve central en la sexualidad femenina su vinculación con lo amoroso, y De Beauvoir señala:

a través de las caricias y la mirada de su pareja [, la mujer] toma deliciosamente conciencia de su cuerpo como deseable. Si él sigue deseándola, ella se adaptará con indulgencia a su marchitez. Pero al primer signo de frialdad, sentirá amargamente su decadencia, se asqueará de su imagen y ya no soportará exponerse a los ojos de otro. (pp. 43I-432)

A tal grado ocurre esa ligazón que a veces "la afectividad misma se embota cuando todo deseo ha muerto" (p. 433).

Por otro lado, hay un tema que llama la atención y que la autora señala respecto a las parejas casadas, pues para ellas su vida sexual tampoco es fácil. Haciendo referencia a una encuesta, encuentra que

las parejas tienen más dificultad de envejecer que los individuos aislados porque las relaciones afectivas de los esposos exasperan y se deterioran. La declinación de la salud, el aislamiento consecutivo a la jubilación y a la partida de los hijos los llevan a vivir casi exclusivamente el uno para el otro. Más que nunca, cada uno pide a su cónyuge protección y amor; y cada uno es menos capaz que nunca de satisfacer ese pedido. [...] La separación asesta a veces un golpe mortal a individuos que literalmente no podían prescindir uno del otro. Pero la coexistencia les ocasiona más tormentos que felicidad. (p. 435)

Esta visión crítica sobre las parejas casadas contrasta con lo que se afirma comúnmente respecto a que vivir en pareja mejora la calidad de vida. Asimismo, es evidente la diferencia con lo que sucede en México respecto a la soledad en la vejez: la presencia prolongada de los hijos dependientes y la asunción de los nietos por los abuelos nunca dejan sola a la pareja. Además, la familia extensa es muy común y crece en tiempos de crisis frente a la familia nuclear. Los mayores viven con mucha frecuencia con las generaciones

\section{0}


posteriores, mientras que en Francia, afirma, "en casi todas partes la célula familiar ha estallado. [...] las más de las veces el padre no se reconoce en su hijo. La nada lo aferra por entero" (p. 470).

Como corolario de su obra, y haciendo explícita una clara filiación marxista, Simone de Beauvoir concluye:

la edad en que comienza la decadencia senil siempre ha dependido de la clase a la que se pertenece [...] el jubilado es igualmente presa de ese terrible flagelo, el tedio [...]. Si el jubilado se desespera por la falta de sentido de su vida presente es porque el sentido de su vida le ha sido escamoteado todo el tiempo. (p. 668)

Y en concordancia con los planteamientos iniciales de su obra, y en su conocido tono político, afirma:

ese es el crimen de nuestra sociedad. Su "política de la vejez" es escandalosa. Pero más escandaloso todavía es el trato que inflige a la mayoría de los hombres en la época de su juventud y su madurez. Prefabrica la condición mutilada y miserable que es su suerte en los últimos años de su vida. [...] ¿Qué debería ser una sociedad para que en su vejez un hombre siga siendo un hombre? La respuesta es sencilla:sería necesario que siempre hubiera sido tratado como un hombre. (p. 669)

Y finaliza diciendo que "Todo el sistema es lo que está en juego y la reivindicación no puede sino ser radical: cambiar la vida" (p. 671).

Lecciones ricas y profundas contiene este maravilloso libro, no sólo en el ámbito de la experiencia humana, sino para las ciencias sociales. Ojalá su lectura sea más común en nuestro medio, en el que los viejos y las viejas merecen ser tratados y atendidos con mucha mayor dignidad. Una tarea fundamental en ese camino sería comenzar a considerarlos como sujetos en el pleno sentido del término, lo cual

Reseñas No.77 
incluye, por supuesto, aceptar y desear la continuidad de su vida sexual y no su abrupta cancelación.

Bibliografía De Beauvoir, S. (20I3). El segundo sexo. México: Debolsillo. 